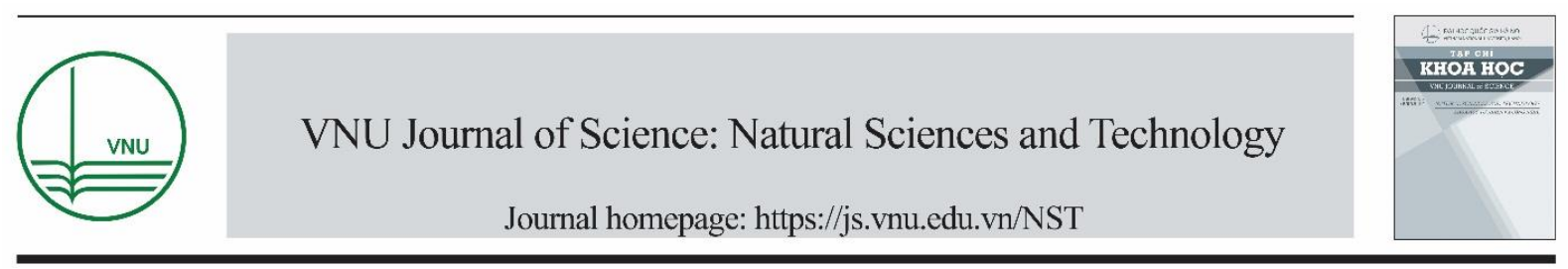

Original Article

\title{
Promotion of Cell Cycle Arrest and Inhibition of Anchorage-independent Growth of Cervical Cancer HeLa Cells by Ethanol Extract of Croton kongensis
}

\author{
Nguyen Thi Bich Loan ${ }^{1,2}$, Nguyen Lai Thanh ${ }^{1}$, Pierre Duez ${ }^{2}$, Nguyen Dinh Thang ${ }^{1, *}$ \\ ${ }^{1}$ VNU University of Science, 334 Nguyen Trai, Thanh Xuan, Hanoi, Vietnam \\ ${ }^{2}$ Unit of Therapeutic Chemistry and Pharmacognosy, University of Mons (UMONS), Belgium
}

Received 10 August 2021

Revised 29 August 2021; Accepted 01 September 2021

\begin{abstract}
Extracts from Croton kongensis (C. kongensis) exhibit anticancer activities on various cancers. However, there is no research conducted to investigate the effects of $C$. kongensis extracts on cervical cancer as well as on zebrafish. In this study, we demonstrated that $C$. kongensis ethanol extract expressed high toxicity to cervical cancer HeLa cells with an IC50 dose of $20.4 \mu \mathrm{g} / \mathrm{mL}$ and to zebrafish embryos with malformations, lethality and hatching inhibition at 72-hpf at the effective dose of $125 \mu \mathrm{g} / \mathrm{mL}$. Interestingly, treatment with $C$. kongensis ethanol extract caused cell cycle arrest at the G2 phase. Particularly, percentages of $C$. kongensis ethanol extract-treated cells in G1, S, G2/M were $70 \%, 6 \%$ and $23 \%$, while percentages of control cells in G1, S, G2/M were $65 \%, 15 \%$ and $18 \%$, respectively. Consistent with cell cycle arrest, the expressions of $C D K N 1 A, C D N K 2 A$ and $p 53$ in $C$. kongensis ethanol extract-treated cells were up-regulated 2.0-, 1.65- and 1.8-fold, respectively. Significantly, treatment with C. kongensis ethanol extract inhibited anchorage-independent growth of HeLa cells; the number of colonies formed in soft-agar of $C$. kongensis ethanol extract-treated cells was only one-fourth of that of control cells. Overall, we suggest that $C$. kongensis ethanol extract should be used as a traditional medicine for treatment of cervical cancer.
\end{abstract}

Keywords: Croton kongensis, HeLa cells, zebrafish, cell cycle arrest, anchorage-independent growth.

\section{Introduction}

Many endemic plants of Vietnam have been used as traditional medicines for thousands of years [1-4].

\footnotetext{
"Corresponding author.

E-mail address: ndthang@hus.edu.vn

https://doi.org/10.25073/2588-1140/vnunst.5298
}

Recently, cervical cancer accounts for about $7.5 \%$ of all female cancer deaths world-wide; of those deaths, approximately $90 \%$ occurred in the developing countries with weakness of public healthcare [5, 6]. In Vietnam, there are more than 5,000 new cases and about 3,000 deaths each year [5]. C. kongensis is one of the endemic medicinal plants displaying different biological activities including antioxidant, antibacterial, anti-inflammatory, and anticancer 
[7-11]. Previous studies demonstrated that the products originating from $C$. kongensis could induce the death of liver cancer cells $[9,11]$, colorectal cancer cell [10], and other cancer cells [7] by activating the apoptosis pathway. However, the molecular mechanisms underlying these actions have not been thoroughly investigated. In addition, so far, no study has addressed the anticancer activity of $C$. kongensis on cervical cancer cells or its putative toxicity on zebrafish embryos, an effective and popular in vivo experimental model for drug screening [12, 13]. Therefore, in this study, we examined the biological and pharmaceutical properties, focusing on cell-targeted toxicity, organism-targeted toxicity (zebrafish) and anticancer activity on cervical cancer in vitro, of the ethanol extract of the medicinal plant $C$. kongensis (CK-EE), an endemic plant of Vietnam used as traditional medicine for a long period.

\section{Materials and Methods}

\subsection{Preparation of Plant Extracts}

The medicinal plant $C$. kongensis was collected from the North-western mountainous areas of Vietnam in the Dry season in 2018-2019. It was identified, coded and placed at the Museum of Biology, Faculty of Biology, VNU University of Science, Vietnam National University, Hanoi, Vietnam. The whole plant was used for extraction. The extraction protocol was described in previous study [14]. The obtained extract was dissolved in DMSO for further analysis and exposure on cells and zebrafish embryos.

\subsection{Cell Culture}

Cervical cancer HeLa (ATCC: CCL-2) cell line was provided by the Health Science Research Resources Bank, Japan and cultured in DMEM, supplemented with $10 \%$ Fetal Bovine Serum (FBS) and $1 \%$ Penicillin/Streptomycin at $37{ }^{\circ} \mathrm{C}$ in $5 \% \mathrm{CO}_{2}$.

\subsection{Zebrafish Embryos Toxicity Test}

Adult zebrafish wild type strains $\mathrm{AB}$ (Danio rerio) [13] were cultured in glass rectangular pools measuring 40x50x30 $\left(\mathrm{cm}^{3}\right)$. Fish were reared in a Techniplast recirculating system under 14:10-h light/dark photocycle. Healthy embryos that showed normal cleavage were distributed into 6-well plates at 25 embryos/well for the embryotoxicity tests. Fish embryo acute toxicity was determined according to guidelines of OECD (OECD 2002) [12].

\subsection{Cellular Toxicity MTT Assay}

MTT (Sigma Chemical Co., St. Louis, MO) assays were carried out as previously described in [15]. A purple formazan product produced by viable cells on the 96-well plate was read using an ELISA reader at $570 \mathrm{~nm}$ for absorbance density values and the percentage of viable cells was calculated.

\subsection{Cell Cycle Analysis}

Cells were stained with propidium iodide (PI) (BD Biosciences) to measure the DNA content by FACSCanto system [16].

\subsection{Real-time PCR Analysis}

Total RNA was isolated from cells using the RNA Isolation Kit (Thermo Scientific, USA), according to the protocol of the Kit. Then cDNA was synthesized from total RNA by reverse transcription, according to the protocol of the cDNA Synthesis Kit (Thermo Scientific, USA). Real-time quantitative RT-PCR with SYBR green was performed using power SYBR1 Green PCR master mix in a LightCycler@96 Instrument.

\subsection{Colony Formation Assay}

A colony formation assay was performed to assess the development of tumor in vitro, according to the previous report [17]. Colonies on the soft agar dish exceeding $50 \mu \mathrm{m}$ in 
diameter were counted and presented as an activity of anchorage-independent growth.

\subsection{Statistical Analysis}

Statistical analysis in this study was performed as previously described [14]. Results from three independent experiments in each group were statistically analyzed by a Student's t-test. The SPSS (version 18) software package (SPSS Japan Inc.) was used for statistical analyses, and the significance level was set to $\mathrm{p}<0.05$.

\section{Results}

\subsection{CK-EE Displayed the Highest Cytotoxicity on Cervical Cancer HeLa Cells}

The ethanol extract of $C$. kongensis (CK-EE) displayed quite high toxic activity on $\mathrm{HeLa}$ cells, with a concentration for fifty percent inhibition (IC50) of $20.4 \mu \mathrm{g} / \mathrm{mL}$, while paclitaxel (taxol), a drug approved by FDA for cancer treatment and used as a positive control, had its value at $13.5 \mathrm{ng} / \mathrm{mL}$ on $\mathrm{HeLa}$ cells (Data not shown). In general, an agent with IC50 value in the range of $0-50 \mu \mathrm{g} / \mathrm{mL}$ is listed as a toxicant; thus the CK-EE was used for further experiments.

\subsection{Toxicity of CK-EE on Zebrafish Embryos}

The effects of CK-EE on the development of zebrafish embryos at different stages were investigated. CK-EE at different concentrations of $0,7.8,15.6,31.3,62.5,125,250,500,1000$ and $2000(\mathrm{mg} / \mathrm{L})$ were applied. At each time point $(24,48,72$, and 96 hours post-fertilization (hpf)), the presence of developmental malformations, lethality and specific endpoint of hatching of the zebrafish embryos (larvae) were assessed (Figure 1A, B, C). At concentrations up to $62.5 \mathrm{mg} / \mathrm{L}$, CK-EE had almost no effect on the development of defects or death of zebrafish larvae with malformation of $5 \%$, lethality of $2 \%$, and hatching efficiency of $90 \%$ (Figure 1A, B, C). However, at $125 \mathrm{mg} / \mathrm{L}$ a big increase in developmental malformations with tail truncation defect, and heart/yolk sac oedema on $60 \%$ larvae at $72 \mathrm{hpf}$ and 96 hpf (Figure 1 E, F), while normal development was observed in Figure 1D. Similarly, at the dose of $125 \mathrm{mg} / \mathrm{L}$, an increase in embryo and larva death was observed with lethality percentages of $10 \%, 35 \%$ and $44 \%$ at $48 \mathrm{hpf}, 72 \mathrm{hpf}$ and $96 \mathrm{hpf}$, respectively (Figure 1B). At high concentration of $250 \mathrm{mg} / \mathrm{L}$, CK-EE expressed its very toxicity to zebrafish embryos because of the developmental defects of $65 \%$ at $72 \mathrm{hpf}$ and $98 \%$ at $96 \mathrm{hpf}$, (Figures 1A, E, F) and death rates of $85 \%$ at $72 \mathrm{hpf}$ and $98 \%$ at $96 \mathrm{hpf}$ (Figures 1B, G). In addition, we monitored the effect of CK-EE at high concentrations on the hatching percentage of the embryos. Normally, the zebrafish hatching takes place between 48 and $72 \mathrm{hpf}$, as illustrated in the control fish. Specifically, at $250 \mathrm{mg} / \mathrm{L}, \mathrm{CK}-\mathrm{EE}$ strongly decreased the hatching percentage of zebrafish embryos to around $10 \%$ at both $72 \mathrm{hpf}$ and $96 \mathrm{hpf}$ (Figure 1C).

\subsection{The CK-EE Induced HeLa Cell Cycle Arrest at the G2 Phase}

HeLa cells were treated with CK-EE or paclitaxel (positive control) at the IC50 doses for $24 \mathrm{hr}$. The cells were stained with propidium iodide (PI). DNA in the nucleus of cells was bound with PI. PI-bound DNA contents were measured by flow cytometer FACs CANTO. The proportions of cells in G1, $\mathrm{S}$, and $\mathrm{G} 2 / \mathrm{M}$ phases were determined and presented as the DNA content histograms in Figure 3. The percentages of the control HeLa cells distributed in the G1, S, and G2/M phases were around $64 \%, 15 \%$ and $18 \%$, respectively (Figure 2A), while the percentages of CK-EE-treated HeLa cells in the G1, S, and $\mathrm{G} 2 / \mathrm{M}$ phases were $70 \%, 6 \%$ and $23 \%$, respectively. These results indicate that CK-EE significantly induced cell cycle arrest in the G2/M phase (Figure 2B). In a similar manner, paclitaxel arrested the cell cycle at the G2/M phase, as indicated by the percentages of cells distributed in the G1, S, and G2/M phases of $36 \%, 21 \%$ and $26 \%$, respectively (Figure $2 \mathrm{C}$ ); however, paclitaxel expressed its higher ability in inducing cell apoptosis with $17 \%$ cells entering apoptotic phase, compared with CK-EE. 

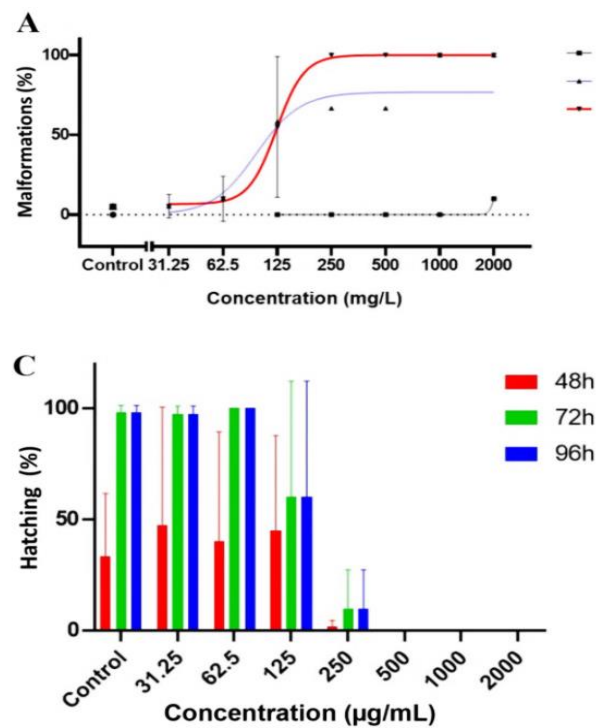
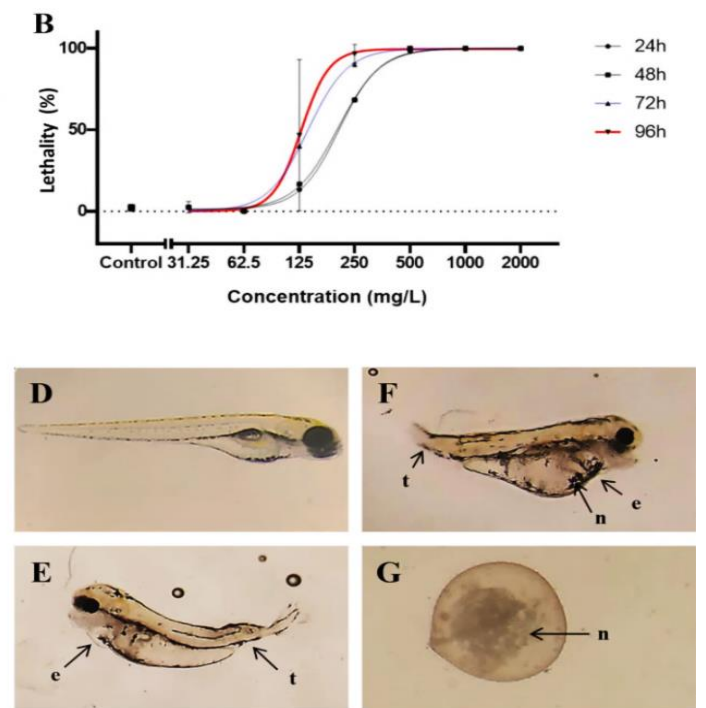

Figure 1. Effect of CK-EE on the development and survival of zebrafish embryos at different time points.

The effects of CK-EE at various doses $(0,7.8,15.6,31.3,62.5,125,250,500,1000$ and $2000(\mathrm{mg} / \mathrm{L})$

on developmental defects (A), lethality (B), and hatching (C) of zebrafish embryos at 48, 72 and $96 \mathrm{hpf}$, respectively, are presented as dose-response curves. Representative images of $96 \mathrm{hpf}$ zebrafish larvae presenting various developmental defects upon CK-EE exposure at different doses; (D) $0 \mathrm{mg} / \mathrm{L}$ (negative control), (E) $62.5 \mathrm{mg} / \mathrm{L}$,

(F) $125 \mathrm{mg} / \mathrm{L},(\mathrm{G}) 250 \mathrm{mg} / \mathrm{L}$. Illustrated defects on larvae include yolk-sac oedema (e), truncate defect (t), and necrosis $(\mathrm{n})$ as indicated with arrows.
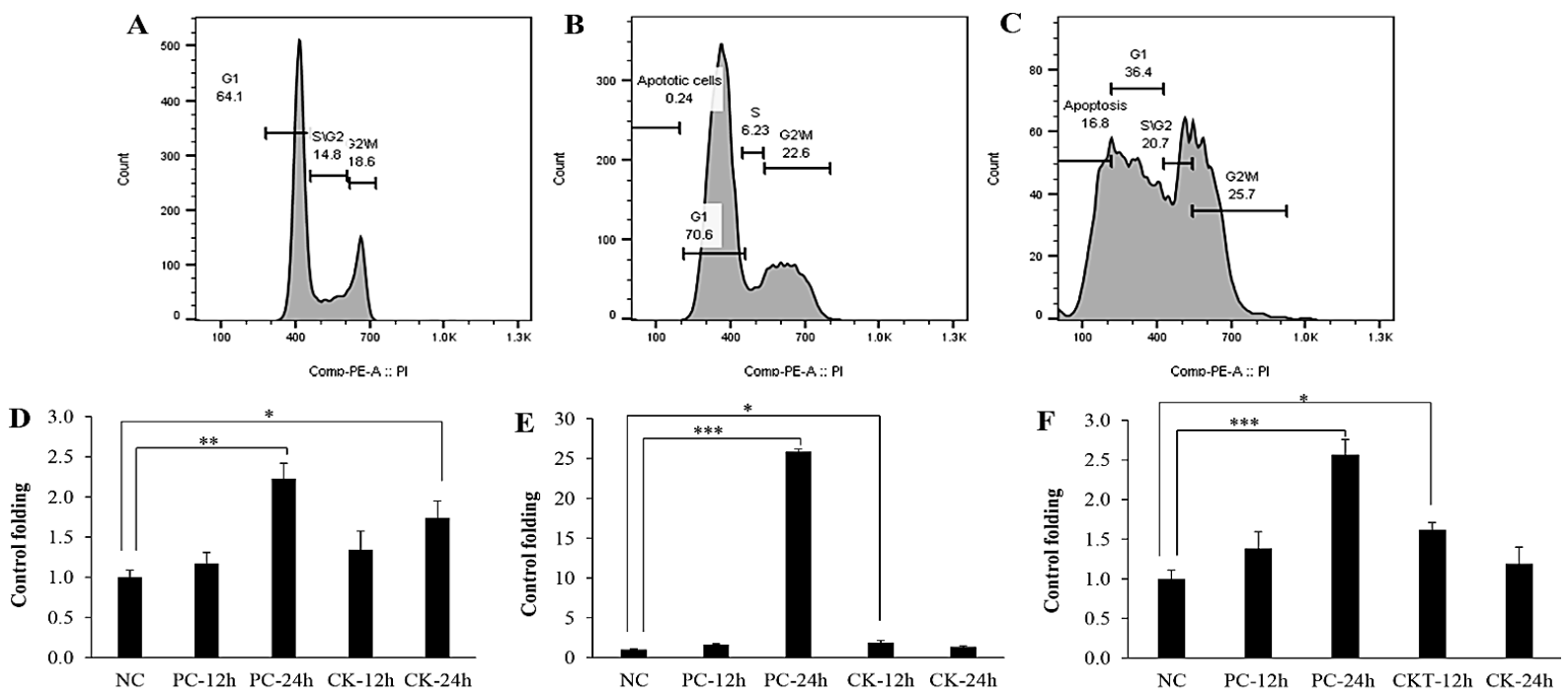

Figure 2. HeLa cells were CK-EE-treated at IC50 dose of $20.4 \mathrm{mg} / \mathrm{L}$ or paclitaxel (positive control) at IC50 dose of $13.5 \mu \mathrm{g} / \mathrm{L}$ for $24 \mathrm{hr}$ before collecting, fixing, staining with propidium iodide (PI) and subjecting to flow cytometry system to measure cellular DNA content. Representative data sets of cell cycle pattern of control HeLa cells (A), CK-EE treatment (B), and paclitaxel treatment (C) were presented. Transcript levels of p53 (D), CDKN1A (E), and CDKN2A (F) in HeLa cells treated with CK-EE and paclitaxel for $12 \mathrm{~h}$ and $24 \mathrm{~h}$. $*, * *$ and $* * *$ significant differences with $\mathrm{P}$ values $<0.05,<0.01$ and $<0.001$, respectively. TBP was used as internal control gene. NC: negative control, PC: positive control. 
Additionally, to study molecular mechanisms underlying the cell cycle arrest, the transcript levels of p53, CDKN1A (encode for $p 21^{C I P I}$ ), and CDKN2A (encode for p16 $6^{I N K 4 A}$ and $p 14^{A R F}$ ) genes that encode for corresponding p53, p21 and p16 proteins, which in turn would regulate the cell cycle were investigated. Importantly, treatment with either CK-EE or paclitaxel significantly induced the transcript levels of p53,CDKN1A and CDKN2A in HeLa cells (Figures 2D, E, F). Interestingly, although CK-EE and paclitaxel promoted the transcript levels of CDKN1A and CDKN2A, CK-EE expressed its effectiveness at earlier time of $12 \mathrm{~h}$, while paclitaxel presented its effectiveness at later time of $24 \mathrm{~h}$. In consistent with G2-phase retardation, the transcript levels of p53,CDKN1A, and CDKN2A in the CK-EE-treated cells were up-regulated 2.0-, 1.65-fold at $24 \mathrm{~h}$ and 1.80-fold, compared with those in the control cells, respectively (Figures 2D, E, F). On the other hand,

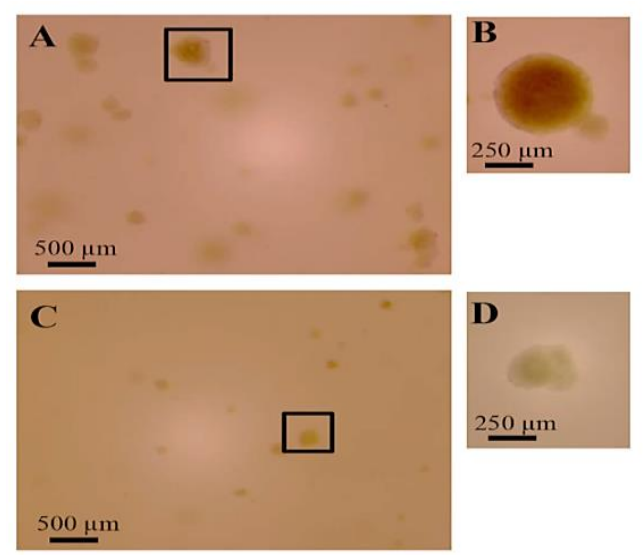

paclitaxel strongly increased the expression levels of both $C D K N 1 A$ and $C D K N 2 A$ genes at the time of $24 \mathrm{~h}$ of 2.2-, 26- and 2.57-fold, respectively (Figures 2D, E, F).

\subsection{CKbilit-EE Inhibited Anchorage- independent Growth Ability of HeLa Cells}

Anchorage-independent growth ability of HeLa cells was assessed by performing a colony formation assay. The results showed that exposure to CK-EE at IC50 dose of $20.4 \mathrm{mg} / \mathrm{mL}$ caused a reduction of colony numbers as well as decreased the size of colonies of cells in soft agar (Figures 3C, D) compared with control cells (Figures 3A, B). Particularly, the number of colonies in case of control cells was 4.2-fold higher than that in CK-EE-treated cells (Figure 3E). Meanwhile, treatment with paclitaxel at the IC50 dose of $13.5 \mathrm{ng} / \mathrm{mL}$ completely inhibited colony formation of cells (Figure 3E).

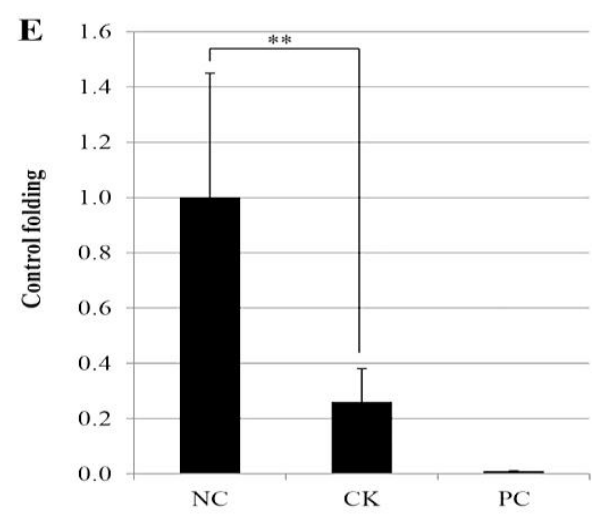

Figure 3. Anchorage-independent growth of HeLa cells. Colonies formed on the soft agar in case of control cells (A and B) and CK-EE-treated cells (C and D) at magnifications of 2X (A and C) and $5 \mathrm{X}(\mathrm{B}$ and $\mathrm{D})$. The differences in colony formation ability on soft agar of HeLa cells are presented in a graph $(\mathrm{E}) . * *$ significant differences with $\mathrm{P}$ values $<0.01$ by Student' t-test.

\section{Discussion}

Previous studies showed that diterpenoids extracted from $C$. kongensis had many biological activities in vitro, including antioxidant, anti-inflammatory, antibacterial, and anticancer [1-4]. Particularly, the anticancer activity of these diterpenoids had been presented on liver cancer cells and colorectal cancer cells by inducing apoptosis via activating related signaling pathways [9-11]. However, so far, the effects of CK-EE on cervical cancer cells as well as on zebrafish (a living organism) have not been examined yet. 
We, for the first time, demonstrated that CK-EE promoted HeLa cell cycle arrest of HeLa cells at the G2/M phase. In consistent with this fact, the expression levels of genes encoding proteins involved in regulation of the cell cycle, including $p 53$, CDKN1A $\left(\mathrm{p} 21^{\mathrm{CIP1}}\right)$, and $C D K N 2 A\left(\mathrm{p} 16^{\mathrm{INK}}\right)$ were examined. Our results showed transcript levels of $p 53$, CDKN1A (p21 $\left.{ }^{\mathrm{CIP1}}\right)$, and CDKN2A (p16 $\left.{ }^{\mathrm{INK}}\right)$ significantly up-regulated in HeLa cells treated with CK-EE. As well known, p53 is generally involved in cell cycle arrest induced by DNA damage [5], and can also stimulate the transcription of $C D K N 1 A$ and $C D K N 2 A[6,18]$, which responses for G1/S phase and G2/M phase of cell cycle $[19,20]$.

Anchorage-independent growth is a hallmark of cancer cells. It represents the proliferative ability of cancer cells in the absence of adhesion to extracellular matrix proteins and correlates closely with tumorigenesis $[21,22]$. Thus, we assessed the anchorage-independent growth ability of cancer cell by conducting colony formation. We found that CK-EE significantly inhibited both number and size of colonies of HeLa cells formed in soft agar. The ability to inhibit the colony formation of cancer cells is one of the most important effects of drug for cancer treatment, especially for cancers with solid tumors [21, 22]. In this study, we revealed the ability of CK-EE in decreasing the anchorage-independent growth of HeLa cells.

Further, we demonstrated that CK-EE at the concentrations below $65 \mathrm{mg} / \mathrm{L}$ had almost no effect on zebrafish embryo development and survival. However, at higher concentrations starting at $125 \mathrm{mg} / \mathrm{L}, \mathrm{CK}-\mathrm{EE}$ strongly induced developmental defects and death of the larvae. These data suggest that further investigations of the effect of CK-EE in vivo are needed before applying on human beings.

\section{Conclusion}

Conclusively, we suggest that CK-EE can be used as a traditional medicine for treatment of cervical cancer; however, the epidemiological data and pharmacokinetic studies should be further addressed. Moreover, because of the ability of CK-EE to cause hatching inhibition, malformations and death of zebrafish larvae, its doses should be applied with due caution.

\section{Acknowledgements}

This research was supported by ARES (Académie de Recherche et d'Enseignement Supérieur) and the Ministry of Cooperation in Belgium.

\section{References}

[1] P. T. Thuong, T. T. Dao, T. H. Pham, P. H. Nguyen, T. V. Le, K. Y. Lee, W. K. Oh, Crotonkinensins A and B, Diterpenoids from the Vietnamese Medicinal Plant Croton Tonkinensis, Journal of Natural Products, Vol. 72, No. 11, 2009, pp.2040-2042.

[2] P. T. Thuong, T. H. Pham, T. V. Le, T. T. Dao, T. T. Dang, Q. T. Nguyen, W. K. Oh, Symmetric Dimers of Ent-kaurane Diterpenoids with Cytotoxic Activity from Croton Tonkinensis, Bioorganic and Medicinal Chemistry Letters, Vol. 22, No. 2, 2012, pp. 1122-1124.

[3] N. H. Nguyen, H. T. Vu, N. D. Le, T. D. Nguyen, H. X. Duong, H. D. Tran, Molecular Identification and Evaluation of the Genetic Diversity of Dendrobium Species Collected in Southern Vietnam, Biology, Vol. 9, No. 4, 2020, pp. 76.

[4] T. M. H. Nguyen, H. L. Le, T. T. Ha, B. H. Bui, N. T. Le, V. H. Nguyen, T. V. A. Nguyen, Inhibitory Effect on Human Platelet Aggregation and Coagulation and Antioxidant Activity of C. Edulis Ker Gawl Rhizome and Its Secondary Metabolites, Journal of Ethnopharmacology, Vol. 263, 2020, pp. 113-136.

[5] H. Sung, J. Ferlay, R. L. Siegel, M. Laversanne, I. Soerjomataram, A. Jemal, F. Bray, Global Cancer Statistics 2020: GLOBOCAN Estimates of Incidence and Mortality Worldwide for 36 Cancers in 185 Countries, CA Cancer, J. Clin, Feb 4, 2021.

[6] The Global Cancer Observatory, Globocan 2020, https:/gco.iarc.fr/today/data/factsheets/populations/70 4-viet-nam-fact-sheets.pdf/, 2020 (accessed on: May $\left.11^{\text {th }}, 2021\right)$.

[7] P. C. Kuo, Y. C. Shen, M. L. Yang, S. H. Wang, T. D. Thang, N. X. Dung, P. C. Chiang, K. H. Lee, 
E. J. Lee, T. S. Wu, Crotonkinins A and B and Related Diterpenoids from Croton Tonkinensis as Anti-inflammatory and Antitumor Agents, Journal of Natural Products, Vol. 70, No. 12, 2007, pp. 1906-1909.

[8] P. C. Kuo, M. L. Yang, T. L. Hwang, Y. Y. Lai, Y. C. Li, T. D. Thang, T. S. Wu, Anti-inflammatory Diterpenoids from Croton Tonkinensis, Journal of Natural Products, Vol. 76, No. 2, 2013, pp. 230-236.

[9] Y. H. Sul, M. S. Lee, E. Y. Cha, P. T. Thuong, N. M. Khoi, I. S. Song, An Ent-kaurane Diterpenoid from Croton Tonkinensis Induces Apoptosis by Regulating AMP-activated Protein Kinase in SK-HEP1 Human Hepatocellular Carcinoma Cells, Biological and Pharmaceutical Bulletin, Vol. 36, No. 1, 2013, pp. 158-164.

[10] P. T. Thuong, N. M. Khoi, S. Ohta, S. Shiota, H. Kanta, K. Takeuchi, F. Ito, Ent-kaurane Diterpenoids from Croton Tonkinensis Induce Apoptosis in Colorectal Cancer Cells Through the Phosphorylation of JNK Mediated by Reactive Oxygen Species and Dual-specificity JNK Kinase MKK4, Anticancer Agents in Medicinal Chemistry, Vol. 14, No. 7, 2014, pp. 1051-1061.

[11] M. Q. Pham, A. L. Iscache, Q. L. Pham, J. E. Gairin, Cytotoxic, Apoptotic, and Sensitization Properties of Ent-kaurane-type Diterpenoids from Croton Tonkinensis Gagnep on Human Liver Cancer HepG2 and Hep3b Cell Lines, Fundamental and Clinical Pharmacology, Vol. 30, No. 2, 2016, pp. 137-146.

[12] OECD, Guidelines for the Testing of Chemicals, Section 4, Test No. 423: Acute Oral Toxicity - acute Toxic Class Method, OECD Publishing, 2002.

[13] K. Ando, S. Fukuhara, N. Izumi, H. Nakajima, H. Fukui, R. N. Kelsh, N. Mochizuki, Clarification of Mural Cell Coverage of Vascular Endothelial Cells by Live Imaging of Zebrafish, Development, Vol. 143, No. 8, 2016, pp. 1328-1339.

[14] N. T B. Loan, K. T. Kien, N. L Thanh, N. T. K. Thanh, N. Q. Huy, P. The-Hai, M. Muller, A. Nachtergael, P. Duez, N. D. Thang, Toxicity and Anti-Proliferative Properties of Anisomeles indica Ethanol Extract on Cervical Cancer HeLa Cells and Zebrafish Embryos, Life, Vol. 11, No. 3, 2021, pp. 257, https://doi.org/10.3390/life11030257.
[15] G. Soman, X. Yang, H. Jiang, S. Giardina, V. Vyas, G. Mitra, J. Yovandich, S. P. Creekmore, T. A. Waldmann, O. Quiñones, W. G. Alvord, MTS Dye Based Colorimetric CTLL-2 Cell Proliferation Assay for Product Release and Stability Monitoring of Interleukin-15: Assay Qualification, Standardization and Statistical Analysis, Journal of Immunological Methods, Vol. 348, No. 1-2, 2009, pp. 83-94.

[16] K. H. Kim, J. M. Sederstrom, Assaying Cell Cycle Status Using Flow Cytometry, Current Protocols in Molecular Biology, Vol. 111, 2015, pp. 28601-28611.

[17] N. D. Thang, I. Yajima, K. Y. Kumasaka, S. Ohnuma et al., Barium Promotes Anchorageindependent Growth and Invasion of Human HaCaT Keratinocytes Via Activation of c-SRC Kinase, PLoS One, Vol. 6, No. 10, 2011, pp. 25636.

[18] A. J. Levine, the Cellular Gatekeeper for Growth and Division, Cell, Vol. 88, 1997, pp. 323.

[19] P. G. G. Hemmati, B. Normand, J. Gillissen, B. Wendt, P. Dörken, T. Daniel, Cooperative Effect of p21Cip1/WAF-1 and 14-3-3sigma on Cell Cycle Arrest and Apoptosis Induction by p14ARF, Oncogene, Vol. 27, 2008, pp. 6707-6719.

[20] C. Romagosa, S. Simonetti, L. L. Vicente, A. Mazo, M. E. Lleonart, J. Castellvi, S. Ramon, Cajal, p16Ink4a Overexpression in Cancer: a Tumor Suppressor Gene Associated with Senescence and High-grade Tumors, Oncogene, Vol. 30, 2011, pp. 2087-2097.

[21] Z. Li, J. Zhao, Y. Du, H. R. Park, S. Y. Sun, L. Bernal-Mizrachi, A. Aitken, F. R. Khuri, H. Fu, Down-regulation of 14-3-3zeta Suppresses Anchorage-independent Growth of Lung Cancer Cells Through Anoikis Activation, Proceedings of the National Academy of Sciences of the United States of America, Vol. 105, No. 1, 2008, pp. 162-167.

[22] F. Weinberg, R. Hamanaka, W. W. Wheaton, S. Weinberg, J. Joseph, M. Lopez, B. Kalyanaraman, G. M. Mutlu, G. R. Budinger, N. S. Chandel, Mitochondrial Metabolism and ROS Generation are Essential for Kras-mediated Tumorigenicity, Proceedings of the National Academy of Sciences of the United States of America, Vol. 107, No. 19, 2010, pp. 8788-8793. 